\title{
Thermal comfort in sustainable buildings: case study Cenpes/UFRJ-RJ/Brazil
}

 \\ \& L. Pinguelli Rosa ${ }^{4}$ \\ ${ }^{I}$ Department of Civil Construction, Urban Engineering Program, \\ Federal University of Rio de Janeiro, UFRJ, Brazil \\ ${ }^{2}$ Department of Civil Construction, Federal University of Rio de Janeiro, \\ UFRJ, Brazil \\ ${ }^{3}$ Department of Architecture and Urbanism, \\ Federal Rural University of Rio de Janeiro, UFRRJ, Brazil \\ ${ }^{4}$ Post-Graduation Program on Energy Planning, \\ Federal University of Rio de Janeiro, COPPE/UFRJ, Brazil
}

\begin{abstract}
The current paper presents the structure of the study designed to evaluate thermal comfort of the constructions that shelter the laboratories and the Central Building in the expansion of Cenpes (Research Center Leopoldo Miguez de Mello) at Rio de Janeiro in Brazil, and the considerations that arose from the interpretation of results. The assumptions of the project involved key aspects such as sustainability and eco-efficiency in design solutions and materials specification. This paper aims to develop an analysis of the studies for the development of the project in environments such as the Central Building and the laboratories of the expansion of Cenpes, focusing on the simulation of the designed environments regarding thermal comfort performance, using software such as Analysis CST and Analysis BIO. The article is structured in four parts: design features of the laboratories and Central Building, environmental comfort criteria adopted in their respective projects, simulation of thermal comfort in the study areas using the software Analysis CST and Analysis BIO and final considerations. This paper intends to provide subsidies to break paradigms that can lead to a new mark to the Brazilian construction industry by adopting rational systems, with reuse, use of natural energy resources and, when possible, reduction of the materials used. As a consequence, a construction that is cleaner, more efficient
\end{abstract}


and has a lower operating cost emerges, due to the various eco-efficient assumptions adopted in the project stage contributing to the materialization of the expected thermal comfort during the preparation of the project. Keywords: sustainability, environmental comfort, Cenpes (Brazil).

\section{Introduction}

\subsection{Sustainable buildings and sustainability}

Throughout history, the architecture has generated several systems to ensure climate protection and environmental comfort: the relation inside/outside, through windows, porches, balconies and patios; the internal organization of space around the central chimney; the use of natural convention by double walls that channel hot air; and buried buildings taking advantage of thermal mass of earth and water to heat or cool, according to the weather [1].

The arise of cities, the need for habitation, infrastructure for new construction, the first oil crisis in 1973, the consequent rise in prices imposed by the exporting countries forced the world to rethink a more sustainable way of life. After the Industrial Revolution, much of the rural population moved to urban centers, attracted by job opportunities, thereby increasing the population and the level of production and environmental pollution, stimulating research for constructive measures less aggressive and less environmental impact [2].

In the late 80 's and early 90 's, sustainability issues came to the agenda of the international architecture and urbanism in an incisive way, bringing new paradigms, especially on the European context. The topic arose with greater emphasis on environmental issues, as a result of the international discussions in the 70's. The attentions were both to the consequences of an energy crisis of global proportions, as well as the environmental impact generated by the consumption of energy, fossil based, added to the forecasts and warnings about the growing world population and the inevitable growth of cities and their demand for all types of resources [3].

Currently much is said about "Sustainable Development" or "eco-efficiency". "Sustainable development" is intended to meet the needs of the present without compromising the ability of future generations to meet their own needs. As for "eco-efficiency" is the production of goods and services at competitive prices that meet human needs and bring quality of life, with a progressive reduction of environmental impacts and intensity of natural resources used during its life cycle at a level at least compatible with the planet's capacity to provide such resources [4].

Finally, due to the maturing of global discussions on the sustainability necessary for the coexistence of species on the planet, the construction of the extension of the building Cenpes, the object of case study in this article, consolidates an important mark in the constant demand to integrate the environment and construction, using the most of natural and energy resources available, thereby reducing the impacts on the ecosystem to which it belongs. 


\subsection{Thermal comfort}

Thermal comfort is defined as the mental state expressed by thermal satisfaction within the surrounding environment. Dissatisfaction can be caused by a sensation of discomfort by heat or cold, when the thermal balance is not stable, i.e., when there are differences between the heat produced by the body and the heat lost to the environment. The international standard to determine thermal comfort is ISO 7730 (1994) [5].

These changes occur all the time and can change direction, in other words, from loss to gain of heat, according to environmental changes, the time (day or night), activity (metabolism) and clothing. The key to the sensation of thermal comfort is to have the sum of these changes zero.

The heat generated by the body, can vary from $100 \mathrm{~W}$ to $1000 \mathrm{~W}$. Some of the generated heat is necessary, as already said, for the physiological functioning of the body, and another part is due to the performance of outside activities. This generation must be dissipated to avoid any overheating of the body. The temperature inside the human body is almost constant, varying between approximately 35 to 37 degrees Celsius. For a person to be in a state of thermal comfort, while performance activities, a tolerance of small fluctuations of this internal temperature can be accepted, and in more extreme situations, a tolerance of variations slightly larger can be taken into consideration to avoid the heat stress [6].

Thus, the activities performed by the human body generate heat, which must be dissipated into the environment avoiding an excessive increase in the internal temperature and maintaining the heat balance of the body. This dissipation occurs through some heat exchange mechanisms, among which: through the skin: sensible heat loss (radiation and convection), latent heat loss (evaporation of sweat and dissipation of moisture from skin) and breathing: sensible heat loss (convection), latent heat loss (evaporation) [7].

\section{Objective}

The objective of this study is to undertake an analysis of the studies for the development of the project based on the environmental comfort in the central building of the expansion of the Cenpes Laboratories, focusing on the projects carried out by simulating the environments designed for performance in thermal comfort, using software (Analysis and Analysis CST BIO) designed to simulate these environments, thus concluding the actual effectiveness of the assumptions made during the development of thermal design for these buildings.

Upon completion of the simulations performed using the software Analysis CST and Analysis Bio, the improvements necessary to meet the thermal comfort of the users will be assessed, judging if they were adequately addressed during the stage of project design, describing the treatments considered for each point of improvement evidenced by the simulation results, identifying also points that were left untreated. 


\section{Methodology}

The methodology adopted for the development of the article was based on information from the executive project designed to build the expansion of the Research Center Leopoldo Americo Miguez de Mello. Based on existing data and, with aiming to characterize the thermal performance of the buildings focus of this study, the environments will be simulated using the software Analysis $\mathrm{BIO}$ and Analysis CST, where the thermal performance of buildings will be demonstrated in accordance with the season the year, the type of used air conditioning and behavioral profile (including clothing) of users. The work developed had a theoretical research on the subject, thus conferring the basis of the closing remarks obtained after the simulations. The article developed, based on a case study, tries to approach the target audience from situations that are likely to occur in the facilities studied, since the data of the developed project was adopted, thus allowing the completion of some suspicion and knowledge of new facts that were not taken into consideration during the preparation of the project. After the development of the simulations it will be evaluated if the main goal of sustainable assumptions was achieved, taken aiming for the thermal comfort of the buildings.

\section{Case study}

The buildings analyzed were the laboratories and the main building, located in the complex of the expansion of Cenpes.

\subsection{Design features of the laboratories and central building}

\subsubsection{Laboratories}

Figure 1 highlights on the master plant the projection area occupied by the existing laboratories in the expansion of the Cenpes.

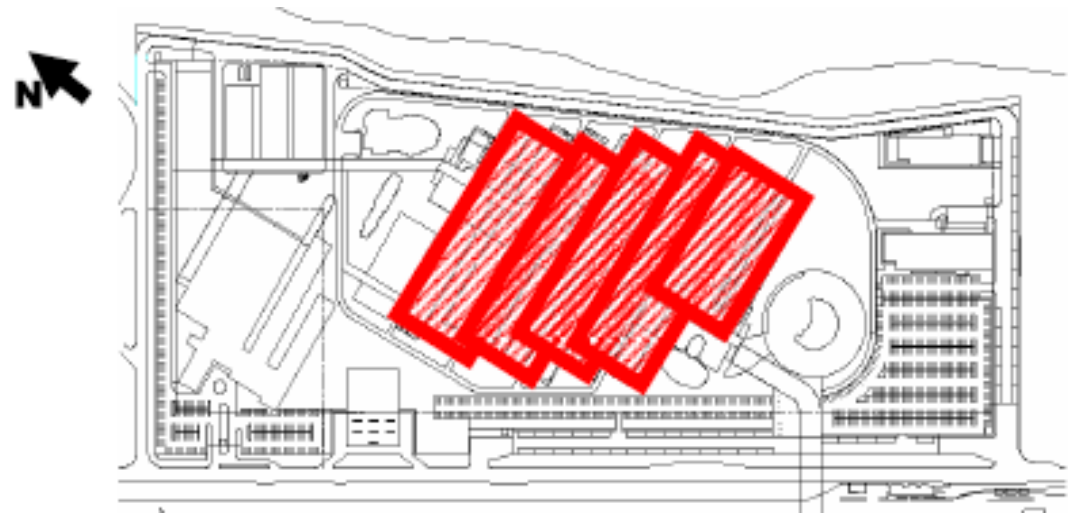

Figure 1: Location of the laboratories in the implementation. 
Each module of the laboratory building is composed of a laboratory, two offices for researchers and an antechamber, interspersed with areas of utilities. The buildings are located on the ground floor and develop into wards, with the major fronts in the east-west direction, facing to a movement of services or to an internal tree-lined street. The main entrance of the offices and laboratories is covered by a concrete deck, which also acts as sun protection for facades and windows of the offices.

The laboratories have been completely sealed and remain under artificial conditioning at $100 \%$ of the time. The offices, although are equipped with airconditioning, may have their windows open, working with natural conditioning, when desirable.

Above the laboratories is located a technical floor where the facilities, the air conditioners and other equipment needed for activities developed will be placed. This space was considered as an area that generated heat to the building.

Under the coverage, on the north side, photovoltaic panels and vertical fins will be placed, acting as the shading of the roof and windows of the laboratory.

\subsubsection{Central building}

Figure 2 highlights on the master plant the projection area occupied by the central building in the expansion of the Cenpes.

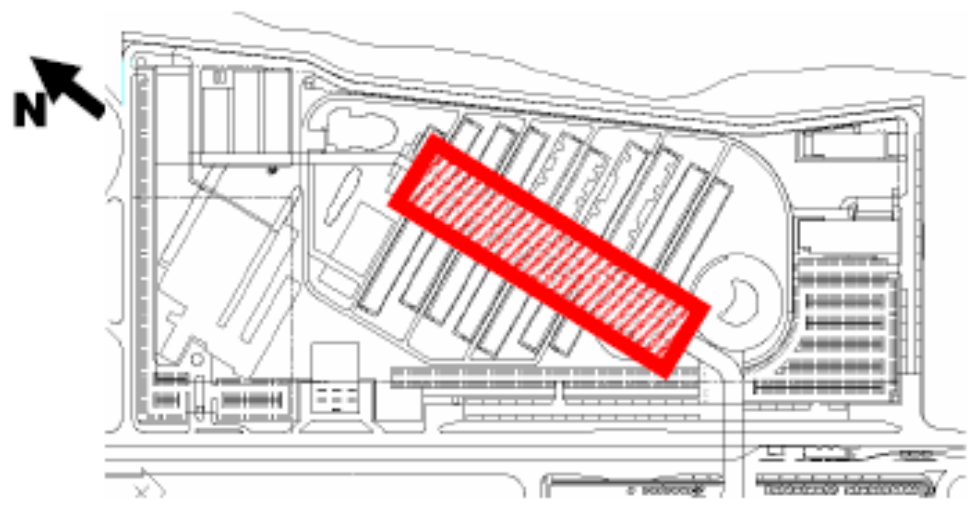

Figure 2: Location of the central building in the implementation.

The Central Building connects the convention center to the laboratory area. It is a suspended building, approximately 245 meters long, where offices for researchers are located. The building is oriented in the north-south axis, meaning that the largest facades are facing east and west. The building is asymmetrical; the east wing has two floors and the west wing, only one.

The orientation of the building makes it difficult to baffle openings, making it necessary to obstruct almost completely the window, which can cause lighting problems. 


\subsection{Criteria for environmental comfort of the projects adopted in the central building and laboratories}

\subsubsection{Artificial conditioning}

To determine the parameters of comfort during artificial conditioning of the building, FUPAM [8] used the procedure of the international standard ISO 7730 (1994) and related (ISO7726: 1998, ISO 8996, 1990, ISO 9920, 1995). The results were compared with the Brazilian standard NBR 6401 (1980) and the Technical Guidance from the National Health Surveillance Agency (ANVISA, 2003).

According to ISO 7730 (1994) [9], the percentage of people dissatisfied (PPD), may not exceed $10 \%$. For personal variables, the metabolic rate (M) adopted is equivalent to sitting manual work in the office or laboratory. Thus, according to ISO 8996 (1990): $\mathrm{M}=70 \mathrm{~W} / \mathrm{m}^{2}$ (1.2 met).

Resistant clothing $\left(\mathrm{I}_{\text {clo }}\right)$ was adopted, equivalent to the set of short-sleeved shirt, light slacks, underwear, shoes and socks. According to ISO 9920 (1995), this clothing set features: $\mathrm{I}_{\text {clo }}=0.5$ clo.

For the climatic variables, the average radiant temperature adopted is numerically equivalent to the air temperature (valid approach due to the shading of roofs and facades). Thus: $\mathrm{T}_{\mathrm{rm}} \approx \mathrm{T}_{\mathrm{bs}}$, therefore, according to ISO 7726 (1998), the operative temperature is numerically equal to the temperature of the air: $\mathrm{T}_{\mathrm{o}}=$ $\mathrm{T}_{\mathrm{bs}}$.

Regarding air speed, for light activity, during the summer (cooling period), with operating temperatures up to $26^{\circ} \mathrm{C}$ (ISO 7730, 1994, ASHRAE 55-1992, 1995): $\mathrm{V}_{\mathrm{ar}}<0.25 \mathrm{~m} / \mathrm{s} \mathrm{T}_{\mathrm{o}} \leq 26^{\circ} \mathrm{C}$. For operating temperatures greater than $26^{\circ} \mathrm{C}$ (ASHRAE 55-1992, 1995): $\mathrm{v}_{\mathrm{ar}} \leq 0.8 \mathrm{~m} / \mathrm{s}$ for $\mathrm{T}_{\mathrm{o}}>26^{\circ} \mathrm{C}$.

Table 1 summarizes the parameters adopted in the project.

Table 1: $\quad$ Conditions adopted in the project - FUPAM [8].

\begin{tabular}{|c|c|c|}
\hline Parameters & Unit & Value \\
\hline Metabolic rate $(\mathrm{M})$ & $\mathrm{W} / \mathrm{m}^{2}$ & $70(1.2 \mathrm{met})$ \\
\hline Resistance (Iclo) & clo & 0.5 \\
\hline Average radiant temperature $\left(\mathrm{T}_{\mathrm{rm}}\right)$ & ${ }^{\circ} \mathrm{C}$ & $\mathrm{T}_{\mathrm{bs}}$ \\
\hline Operative temperature $\left(\mathrm{T}_{\mathrm{o}}\right)$ & ${ }^{\circ} \mathrm{C}$ & $\mathrm{T}_{\mathrm{bs}}$ \\
\hline Air speed $\left(\mathrm{v}_{\mathrm{ar}}\right)-\mathrm{T}_{\mathrm{o}} \leq 26^{\circ} \mathrm{C}$ & $\mathrm{m} / \mathrm{s}$ & 0.25 \\
\hline Air speed $\left(\mathrm{v}_{\mathrm{ar}}\right)-\mathrm{T}_{\mathrm{o}}>26^{\circ} \mathrm{C}$ & $\mathrm{m} / \mathrm{s}$ & 0.8 \\
\hline
\end{tabular}

\subsubsection{Natural conditioning}

According to ASRHAE [9], the Effective Temperature (ET*) is the operating temperature of an environment at $50 \%$ of relative air humidity, which would cause the same sensible and latent heat exchanges experienced by the user in the environment under study. 
$\mathrm{ET}^{*}$ is calculated by the following equation:

$$
\mathrm{ET}^{*}=\mathrm{To}+\mathrm{w} \cdot \mathrm{I}_{\mathrm{m}} \cdot \mathrm{LR} \cdot(\mathrm{pa}-0.5 \cdot \mathrm{psET} *)
$$

where:

$$
\left\{\begin{array}{l}
\mathrm{T}_{\mathrm{o}} \text { : operative temperature; } \\
\mathrm{w}: \text { skin humidity; } \\
\mathrm{I}_{\mathrm{m}} \text { : clothing moisture permeability; } \\
\text { LR: Lewis relation; } \\
\text { pa: vapor pressure and } \\
\text { psET*: saturation pressure in the effective temperature. }
\end{array}\right.
$$

The operating temperature is the uniform temperature of a hypothetical environment with an imaginary black envelope in which an occupant would produce the radiant and convective heat transfer to the non uniform real environment. Numerically, the average is between the dry bulb temperature of air $\left(\mathrm{T}_{\mathrm{bs}}\right)$ and the average radiant temperature $\left(\mathrm{T}_{\mathrm{rm}}\right)$, weighted by their respective heat transfer coefficients (hc and hr) [8].

Thereby, equation (2) is:

$$
\mathrm{To}=\mathrm{h}_{\mathrm{r}} \cdot \mathrm{T}_{\mathrm{rm}}+\mathrm{h}_{\mathrm{c}} \cdot \mathrm{T}_{\mathrm{bs}} /(\mathrm{hr}+\mathrm{hc})
$$

where: $\quad\left\{\begin{array}{l}h_{\mathrm{r}}: \text { coefficient of radioactive exchange; } \\ \mathrm{h}_{\mathrm{c}}: \text { coefficient of convective exchange; } \\ \mathrm{T}_{\mathrm{rm}}: \text { average radiant temperature; } \\ \mathrm{T}_{\mathrm{bs}}: \text { dry bulb temperature. }\end{array}\right.$

Usually for the calculation of ET*, it is assumed that the effective temperature is given by lines on the psychometric chart, passing through the point where the relative humidity is $50 \%$ for that temperature. The slope of these lines is equal to 0.023 $\left(\mathrm{ET}^{*}\right.$ - 14), when ET* $<30$, and 0.028 $\left(\mathrm{ET}^{*}\right.$ - 14) when $\mathrm{ET}^{*}>30$ [9].

Thus, having the operative temperature and absolute humidity of a point, it was possible, through iterative calculation, to find the effective temperature for that condition. To illustrate the significance of this percentage, table 2 indicates some relations between $\mathrm{ET}^{*}$ and pairs of UR and $\mathrm{T}_{\mathrm{o}}$.

Table 2: $\quad$ Values of operative temperature and relative humidity equivalent to some effective temperatures.

\begin{tabular}{|c|c|c|}
\hline $\mathrm{ET}^{*}\left({ }^{\circ} \mathrm{C}\right)$ & $\mathrm{T}_{\mathrm{o}}\left({ }^{\circ} \mathrm{C}\right)$ & $\mathrm{UR}(\%)$ \\
\hline 25 & 23 & 100 \\
\hline 25 & 25 & 50 \\
\hline 25 & 27 & 9 \\
\hline 30 & 27 & 95 \\
\hline 30 & 30 & 50 \\
\hline 30 & 35 & 6 \\
\hline
\end{tabular}


The comfort temperature $\left(\mathrm{T}_{\mathrm{c}}\right)$ is given by equation (3):

$$
\mathrm{T}_{\mathrm{c}}=18,9+0,255 \cdot \mathrm{ET}^{*} \text { external }
$$

Within a range of tolerance of $\pm 2.5^{\circ} \mathrm{C}$ of temperature, $90 \%$ or more of the occupants would be satisfied with the thermal conditions of the environment. Assuming a tolerance of $\pm 3.5^{\circ} \mathrm{C}$, the satisfaction rate obtained would be $80 \%$.

The effective temperatures for each hour of the external annual climate data base were then calculated, assuming $T_{o}=T_{b s}$. The effective temperature used in the calculation of $T_{c}$ is the average temperature of all hours of the last 30 days. Thus, to February 15, at 15 hours, the external ET* used in the calculation of the $\mathrm{T}_{\mathrm{c}}$ is the average of all effective temperatures from the period between $14 \mathrm{pm}$, on January 16, until 14 pm, on February 15.

\subsection{Simulation of thermal comfort in the environments studied using the Analysis CST and Analysis BIO}

\subsubsection{Analysis CST}

This program, developed in LabEEE/UFSC, aims to make more accessible the method developed by Fanger. Through the environmental conditions and human variables such as activity and clothing, the Analysis CST indicates the PMV and PPD for the environment in question in the module for evaluation of thermal comfort, and the state of thermal stress by cold or heat in the module for stress [4].

Figure 3 shows graphical output PMV and PPD and figure 4 shows the state of comfort.

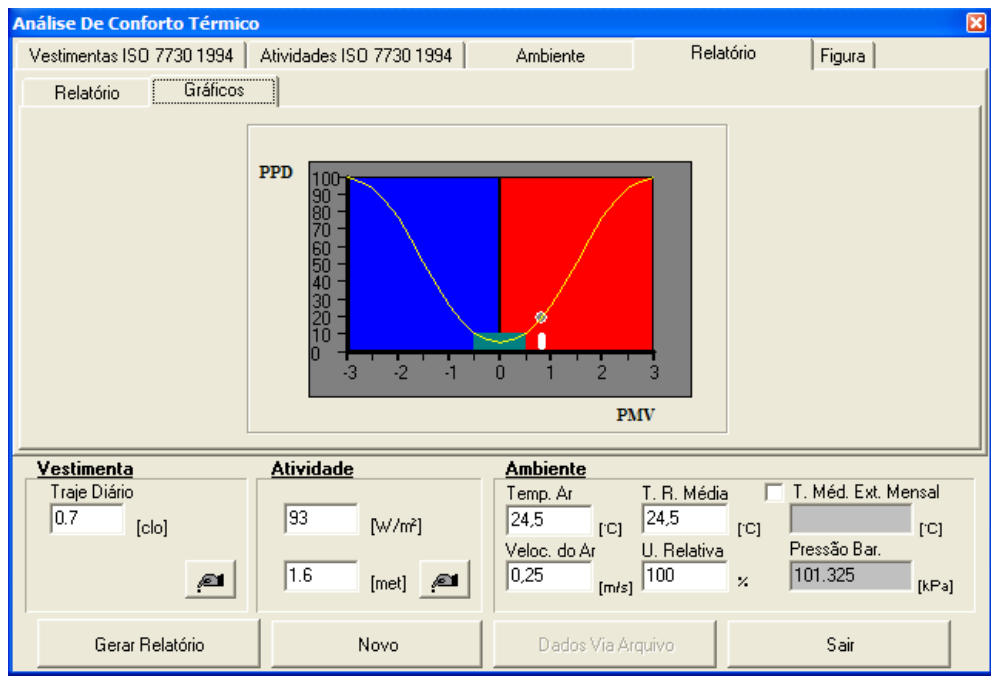

Figure 3: $\quad$ Software analysis CST - graphical output PMV and PPD. 


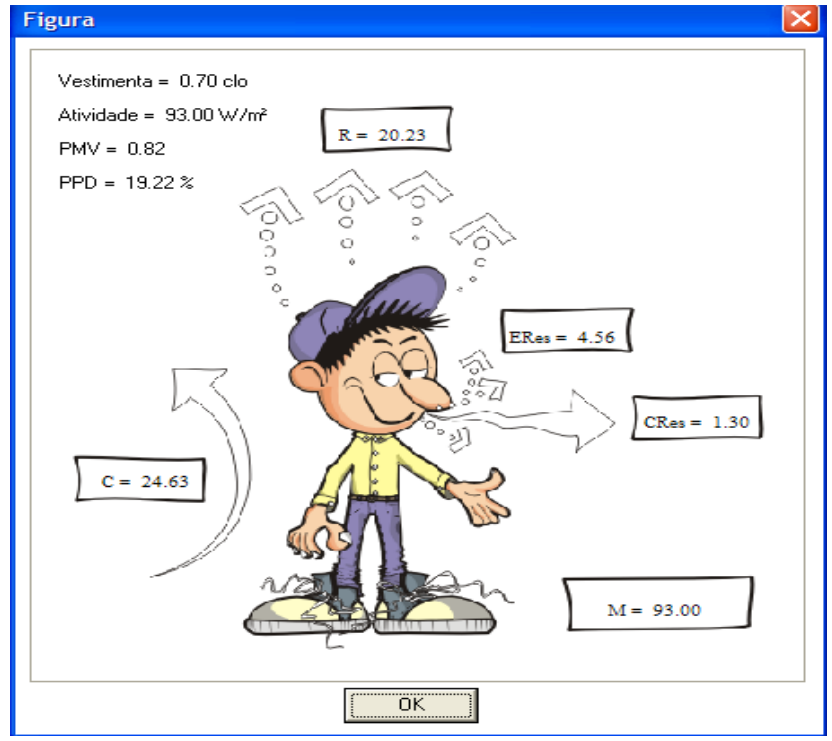

Figure 4: $\quad$ Software analysis CST - state of comfort.

The environments from the laboratories and the center building were studied. The simulation software Analysis CST focused on the verification of the thermal comfort of the environments studied in two conditions: environments with artificial conditioning and environments with natural conditioning. For the latter condition, the environments were simulated for the four seasons and their respective periods of observation, namely: autumn (March 21 to June 21), winter (21 June to 23 September), spring (23 September to 21 December) and summer (December 21 to March 21).

\subsubsection{Analysis BIO}

Through reference climatic data the bioclimatic strategies most appropriate for each location can be determined through the Program Analysis Bio. The program can assess the normal climatological weather data, using the TRY files and/or manually entered data. Figure 5 shows the example of a bioclimatic letter to the city of Rio de Janeiro, TRY produced for the city in 1963 [5].

Through the climate data obtained from the reference bioclimatic diagram of Givoni [10] regarding the city of Rio de Janeiro, the architectural and constructive strategies adopted for the design of the buildings studied in the expansion of Cenpes can be evaluated, according to the results obtained after the simulation on the software Analysis Bio. The TRY file from the software can be used to develop an evaluation for each season of the year. The TRY file corresponds to the set of measurements observed over a period, allowing the elaboration of the bioclimatic diagram for the municipality of Rio de Janeiro. 


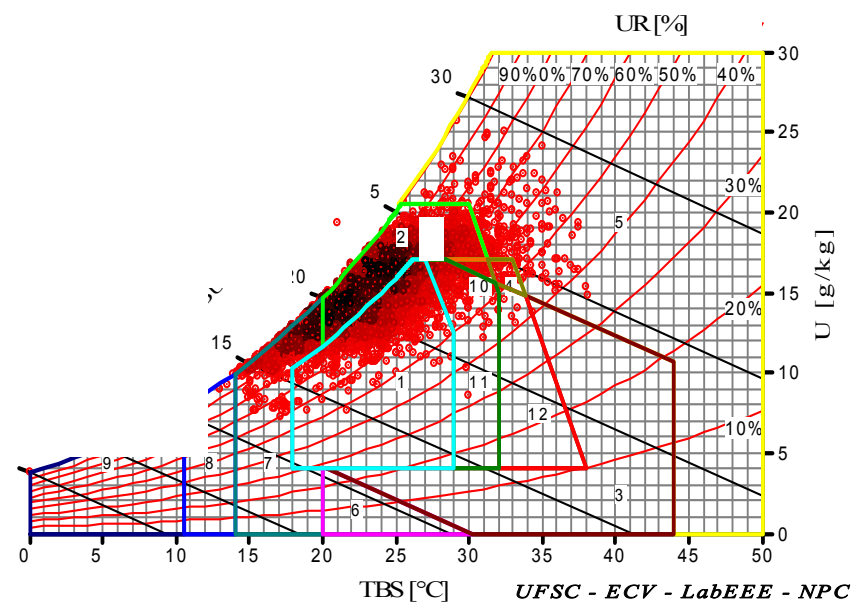

Figure 5: $\quad$ Sample bioclimatic letter - Rio de Janeiro - Brazil.

\subsubsection{Results}

In the simulations with the software Analysis CST and Analysis Bio for the summer season, there was clearly a discomfort due to heat, especially for the percentage of PPD equal to $36.06 \%$ and comfort in only $11.5 \%$ of the season period. The need for artificial conditioning in most of the season period is observed, even with all the architectural assumptions to minimize the climate effects of the region of the building, although there are periods on rare occasions that artificial conditioning is not required, allowing the use of natural ventilation in the environment, thus providing a gain in energy savings, opportunity that would not exist during this time of year if the comfort conditions were not thought with the use of available natural resources.

In the simulations with the software Analysis CST and Analysis Bio for the autumn season, the results expected were not obtained, as the PPD percentages were equal to $19.22 \%$ and comfort in only $30.5 \%$ of the period, that is, although only $19.22 \%$ of users are feeling uncomfortable in accordance with the activities carried out and used clothing, in only $30.5 \%$ of the period, natural conditions of comfort are being accomplished. This result is interpreted as most users at this time of year to feel comfortable performing their respective activities, the local environment allows the comfort condition in only $30.5 \%$ of the period analyzed in terms of natural climate.

In the simulations with the software Analysis CST and Analysis Bio for the winter season, the results were completely controversial given the fact that the PPD achieved a percentage of $7.97 \%$ of comfort for the users of the environments studied, excellent result in terms of natural conditioning, and comfort in only $26.08 \%$ for the period observed. That happens mainly because, for this season, a concern must be observed not only for the discomfort caused by heat, but also for the discomfort caused by cold, as can be clearly noted in the simulations. This fact was duly perceived during the stages of simulations of 
comfort for the elaboration of the project for the buildings under study, where materials with high thermal inertia were used in addition to form a large glass area allowing the inner solar heating. Solving the equation for strategies that shared space with ventilation studies for the environment, a great chance of success in the strategy of natural conditioning in most of this season since $72.4 \%$ of comfort concerning this period is based on the adoption of this strategy. Concluding that this time of year that will be the less demanding period for artificial conditioning on environments studied.

In the simulations with the software Analysis CST and Analysis Bio for the spring season, since this is the season that marks the approach of the trajectory of rotation of the earth to the sun, before the summer, the characteristics were similar to those observed in autumn, although with significantly greater heat discomfort. With a PPD percentage of $14.4 \%$ and comfort conditions in $26.79 \%$ of the observed period, this season will be, as the summer, a large consumer of energy for artificial conditioning of the environments, allowing in some periods the use of natural resources.

\section{Final considerations}

This study aimed to undertake an analysis of the studies for the development of the project on environmental comfort in the central building and laboratories of the expansion of Cenpes, simulating the environments designed for thermal comfort performance, using software designed to simulate these environments.

The results extracted after analysis of the simulations performed by the software Analysis CST and Analysis Bio to analyze comfort conditions in different aspects are presented. While the first assesses the comfort conditions in accordance with the professional activities carried out by users and their clothing, the second simulates situations of comfort with the local environmental characteristics and the materials used in buildings.

All the effort devoted during the project developed for the implementation of the expansion of Cenpes, particularly for the buildings introduced as case study, was rewarded with the return on energy efficiency and reduction in consumption, besides financial savings, reduction in the use of raw material at the beginning of the supply chain, and the main objective of the project, which was to encourage the adoption of studies focused on thermal comfort and other indirect earnings, aiming not only an optimization of results, but also to become widespread in the near future for architecture and engineering projects developed in Brazil.

\section{References}

[1] Acselrad, Henri. A Duração das Cidades: Sustentabilidade e Risco nas populações urbanas. DP\&A, Rio de Janeiro, 2001.

[2] Alexander, Cristopher et alli, A Pattern Language, Towns, Buildings, Construction, Oxford, N.Y., 1977.

[3] Gauzin-Muller, D. Arquitectura Ecológica. Barcelona: Gustavo Gilli, 2002. $286 \mathrm{p}$. 
[4] Lamberts, R. et al. Desempenho térmico de edificações. Apostila versão 2005. Florianópolis, 2005. In: www.labeee.ufsc.br, Access on 07/01/2008.

[5] Lamberts, R.; Dutra, L.; Pereira, F. Eficiência Energética na Arquitetura. São Paulo: PW, 1997.

[6] Grzybowski, G. Conforto Térmico na Escola Pública em Cuibá - MT: Estudo de Caso. 2004. Dissertação (Mestrado em Física e Meio Ambiente Programa de Pós Graduação em Física e Meio Ambiente - UFMT, Cuiabá.)

[7] Rown, G. Sol, Vento e Luz, Estrategias Para O Projeto De Arquitetura . (2 ${ }^{\text {nd }}$ Ed) Ed: J Wiley, 2001.

[8] FUPAM, Conforto e desempenho térmico nas edificações I e II, Fundação para Pesquisa Ambiental, São Paulo, 2004.

[9] ASHRAE STANDARD 90.1-1999: Energy Standard for Buildings Except Low-Rise Residential Buildings. Atlanta: ASHRAE, 1999. 160 p.

[10] Givoni, B. Comfort, climate, analysis and building design guidelines. Energy and Building, vol. 18, pp. 11-23, July/1992. 